\title{
Preparation of aminoethyl glycosides for glycoconjugation
}

\author{
Robert Šardzík, Gavin T. Noble, Martin J. Weissenborn, Andrew Martin, \\ Simon J. Webb and Sabine L. Flitsch*
}

\section{Full Research Paper}

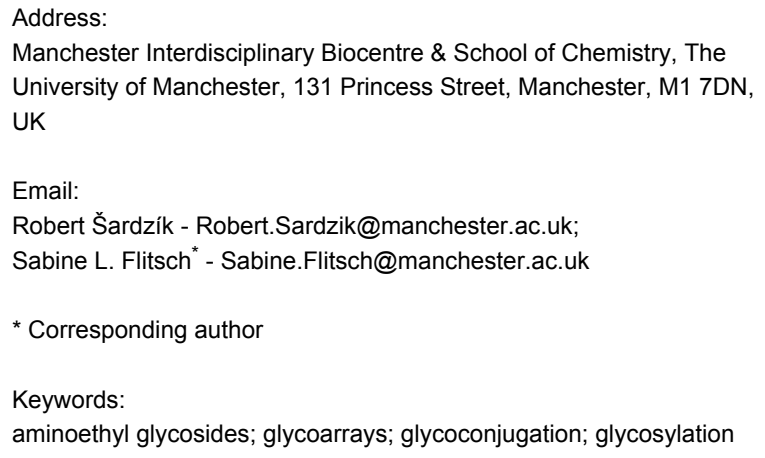

Manchester Interdisciplinary Biocentre \& School of Chemistry, The University of Manchester, 131 Princess Street, Manchester, M1 7DN, UK

Email:

Robert Šardzík - Robert.Sardzik@manchester.ac.uk;

Sabine L. Flitsch* - Sabine.Flitsch@manchester.ac.uk

* Corresponding author

Keywords:

aminoethyl glycosides; glycoarrays; glycoconjugation; glycosylation

\author{
Beilstein J. Org. Chem. 2010, 6, 699-703. \\ doi:10.3762/bjoc.6.81 \\ Received: 26 May 2010 \\ Accepted: 21 July 2010 \\ Published: 29 July 2010 \\ Guest Editor: T. K. Lindhorst \\ (c) 2010 Šardzík et al; licensee Beilstein-Institut. \\ License and terms: see end of document.
}

\begin{abstract}
The synthesis of a number of aminoethyl glycosides of cell-surface carbohydrates, which are important intermediates for glycoarray synthesis, is described. A set of protocols was developed which provide these intermediates, in a short number of steps, from commercially available starting materials.
\end{abstract}

\section{Introduction}

The chemical conjugation of carbohydrates through the anomeric centre to biomolecules such as peptides, proteins, lipids, metabolites and to array surfaces is an important synthetic challenge [1-5]. A diverse range of linkers and spacers has been described in the literature [2-12], among which aminoalkyl glycosides have become the most popular, in particular the aminoethyl linker. This linker has been tested in a large number of arrays and appears to be biocompatible in array screening $[2,3,7]$. Given that aminoethyl glycosides are conveniently conjugated to surfaces containing activated carboxylates, they have become a useful generic anomeric functional group for glycoconjugation. The importance of this linker merits efforts into finding a robust synthetic method than can be used by scientists who are not experienced in carbohydrate syn- thesis. Here we describe a systematic study with the aim of finding such robust and efficient methods for a number of commonly used mono- and disaccharides starting from commercially available reagents and with a minimal number of steps. In our studies no such general aminoethylation method that was applicable to all targets was found, which rather suggests that protocols need to be tailored for each sugar.

\section{Results and Discussion Coupling reactions}

Aminoethyl glycosides have previously been generated in a number of ways. Free sugars have been glycosylated with 2-chloroethanol under acid catalysis, followed by peracetylation, nucleophilic substitution with azide and finally, reduction 


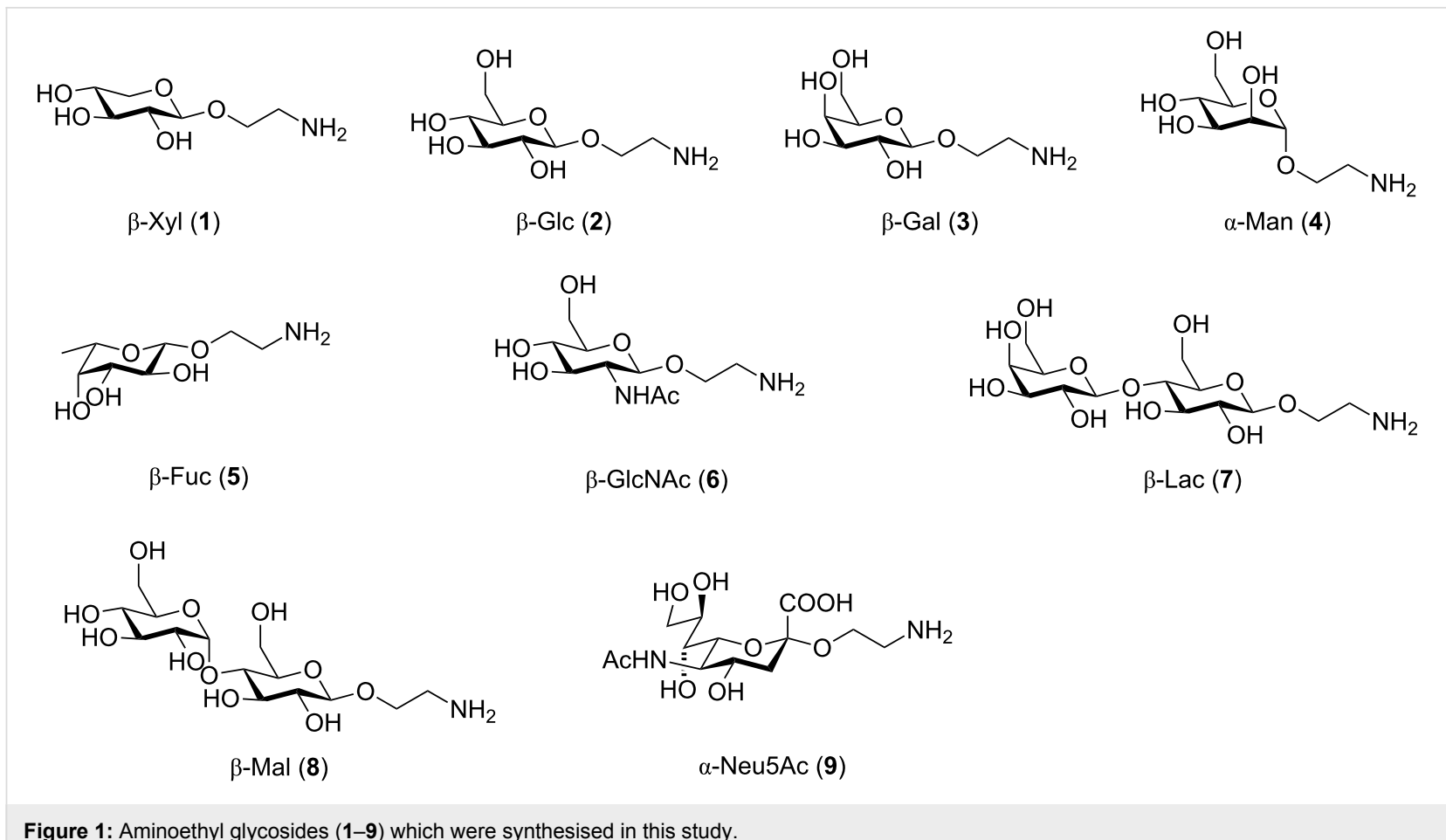

of the azido group $[13,14]$. Alternatively, the carbohydrate was first activated as the trichloroacetimidate or bromide followed by glycosylation with $N$-Cbz-aminoethanol [15], bromoethanol [16] or azidoethanol [17] and subsequently transformed into the amine.

In the interest of finding fast reliable methods, we have investigated two general aminoethylation protocols: First, the direct glycosylation of peracetylated sugars, which can be either purchased or easily prepared from free sugars and can be used without purification. Where these proved to be unreactive, the anomeric acetates were converted to glycosyl bromides, usually in quantitative yields, and products were used without further purification. Where possible, $\mathrm{N}$-Cbz-protected aminoethanol was used as the glycosyl acceptor because it is commercially available, crystalline and can be easily deprotected in one step avoiding use of azides. Figure 1 lists the target aminoethyl glycosides (1-9) generated in this study (q.v. Scheme 1 and Table 1).

The key glycosylation step is shown in Scheme 1 and the results of the different glycosylation reactions are summarised in Table 1 .

Fully protected xylopyranoside $\mathbf{1 0}$ could be prepared both from the corresponding bromide as well as the acetate (the $\beta$-anomer was prepared from xylose with sodium acetate in acetic anhydride) in similar yields. In each case both anomers were formed

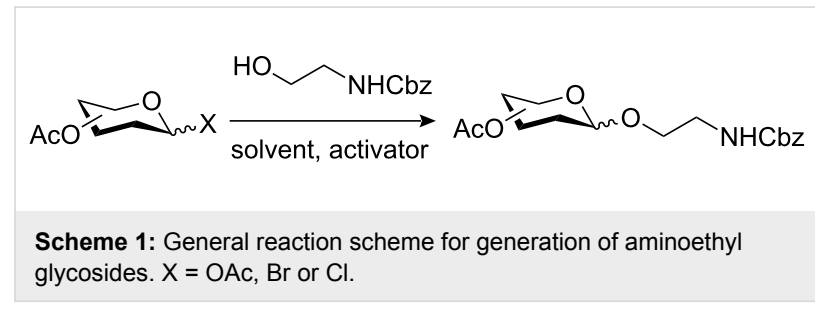

with moderate selectivity and from the reaction mixture the pure $\beta$-anomer ( $>95: 5)$ was isolated by column chromatography.

The glucoside 11, galactoside $\mathbf{1 2}$ and mannoside $\mathbf{1 3}$ were prepared in moderate to good yield directly from the acetate ( $\mathrm{X}=\mathrm{OAc}$ in Scheme 1) giving rapid access to these monosaccharide derivatives.

The fucoside $\mathbf{1 4}$ was generated both from the acetate and bromide. Higher alpha selectivity was observed with the bromide $(\alpha / \beta$ ratio of crude product $82: 18)$.

$\mathrm{N}$-Acetylglucosamine $\mathbf{1 5}$ was successfully prepared from the $\beta$-acetate using $\mathrm{SnCl}_{4}$ (method $\mathrm{D}$ ). When starting from the $\alpha$-acetate, no reaction was observed and only starting material could be recovered. Under microwave conditions (method B or using other Lewis acids as $\mathrm{Yb}(\mathrm{OTf})_{3}$ in $\mathrm{DCM}, 90{ }^{\circ} \mathrm{C}, 30 \mathrm{~min}$, $200 \mathrm{~W}$ ) the reaction was not reproducible, giving low yields and leading to decomposition products. 
Table 1: Results of glycosylation reactions as shown in Scheme 1.

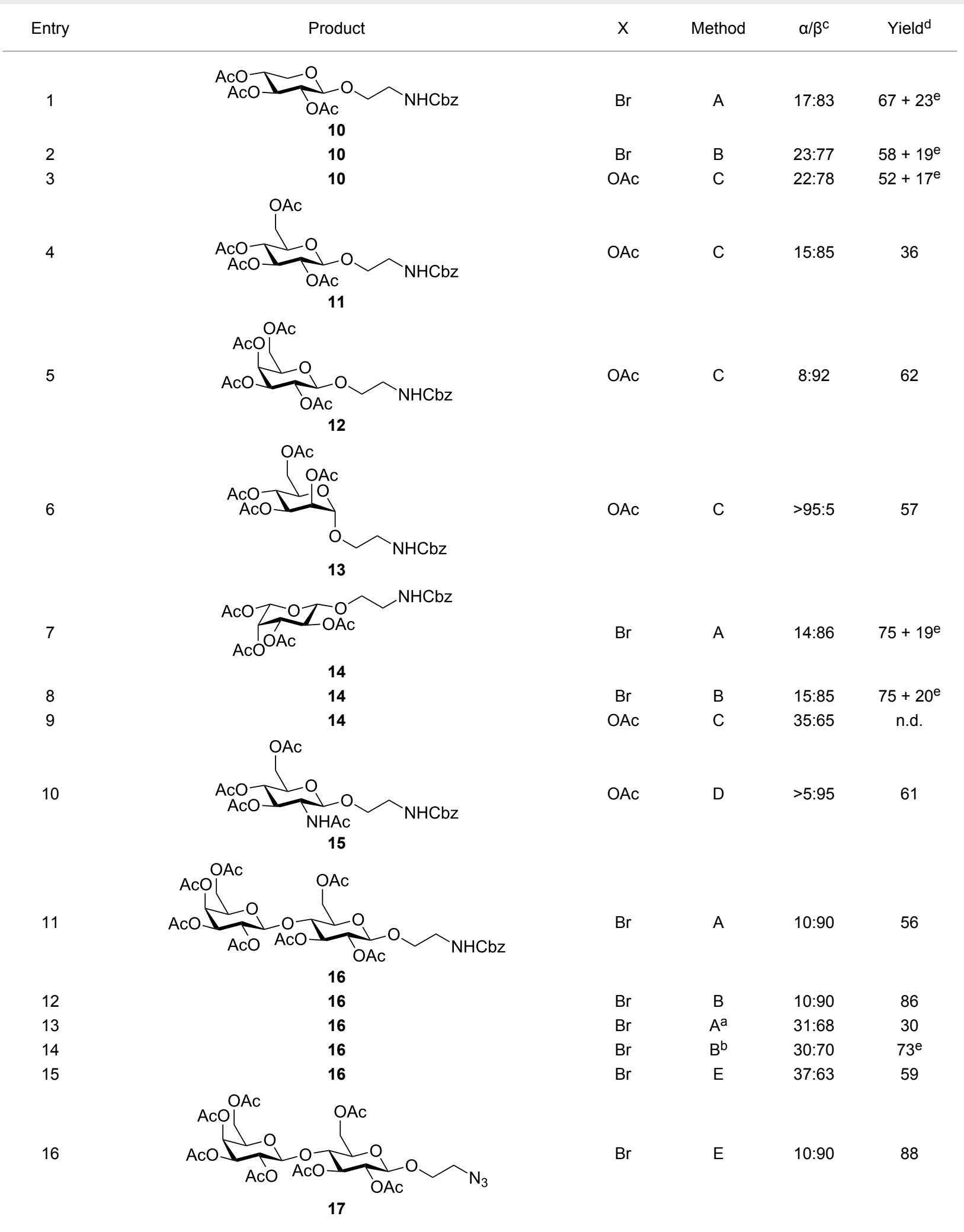


Table 1: Results of glycosylation reactions as shown in Scheme 1. (continued)

17

18

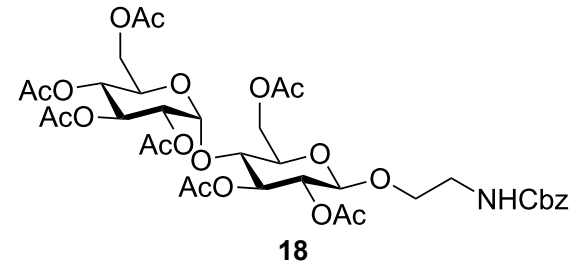

AcHN垈
$\mathrm{Br}$

$\mathrm{Cl}$
$14: 86$

47

$\mathrm{F}$

10:90

70

19

aThe reaction was performed overnight at r.t. ${ }^{b}$ The reaction was performed in $\mathrm{CH}_{2} \mathrm{Cl}_{2} .{ }^{\mathrm{c}}$ determined by ${ }^{13} \mathrm{C}$ NMR from crude reaction mixture. ${ }^{\mathrm{d}}$ Yield of pure major anomer (>95:5) after column chromatography. ${ }^{e}$ Mixture of both anomers. Method $\mathrm{A}: \mathrm{Hg}(\mathrm{CN})_{2}, \mathrm{CH}_{3} \mathrm{CN}, 60^{\circ} \mathrm{C}, 2-4 \mathrm{~h}$. Method B: $\mathrm{Hg}(\mathrm{CN})_{2}$, $\mathrm{CH}_{3} \mathrm{CN}, 90^{\circ} \mathrm{C}$, microwave, $200 \mathrm{~W}, 15 \mathrm{~min}$. Method C: $\mathrm{BF}_{3} \cdot \mathrm{Et}_{2} \mathrm{O}, \mathrm{CH}_{3} \mathrm{CN}, 0{ }^{\circ} \mathrm{C}, 1 \mathrm{~h}$, r.t., overnight. Method D: $\mathrm{SnCl}_{4}, \mathrm{CH}_{3} \mathrm{CN}, 60^{\circ} \mathrm{C}, 16 \mathrm{~h}$. Method E: $\mathrm{Hg}(\mathrm{CN})_{2}, \mathrm{HgBr}_{2}, \mathrm{CH}_{3} \mathrm{CN}$, r.t., overnight. Method $\mathrm{F}: \mathrm{Ag}_{2} \mathrm{CO}_{3}, \mathrm{CH}_{2} \mathrm{Cl}_{2}$, r.t., overnight.

Lactose is both cheap and readily available. It is an important component of glycoprotein glycans and also a substrate for sialyltransferases to generate biologically important sialyllactosides. The aminoethyl lactoside $\mathbf{1 6}$ was prepared in greatest yield from the bromide and attempts to prepare $\mathbf{1 6}$ directly from the acetate using $\mathrm{BF}_{3} \cdot \mathrm{Et}_{2} \mathrm{O}$ as the activator only resulted in decomposition.

A number of reaction conditions for generating $\mathbf{1 6}$ from the bromide with $\mathrm{N}$-Cbz-aminoethanol were investigated. With $\mathrm{Ag}_{2} \mathrm{CO}_{3}$ in dichloromethane at room temperature low yields of product $\mathbf{1 6}$ along with a number of side-products (orthoester, elimination or hydrolysis) were observed and the product was difficult to separate from starting materials, in particular the $\mathrm{N}$-Cbz-aminoethanol. With $\mathrm{Hg}(\mathrm{CN})_{2}$, or the more reactive $\mathrm{Hg}(\mathrm{CN})_{2} / \mathrm{HgBr}_{2}$-mixture, in dichloromethane or acetonitrile, glycosylation was more successful, but both anomers were generated. Given the problems previously encountered with purification, the glycosylation with $\mathrm{Hg}(\mathrm{CN})_{2}$ was further optimised by increasing both the temperature and the amount of acceptor. The problem of separation of the alcohol from the product was solved by acetylation of the crude reaction mixture to lower the polarity of the free alcohol. Attempts to speed up the reaction by heating led to the observation that in acetonitrile predominantly one $(\beta)$ anomer is formed, but anomerisation occurs with longer reaction times. In dichloromethane both anomers were formed. The best reaction conditions were combined to give Method A. The success of Method A led to attempts to improve the method further and to use microwave irradiation as in method B. Method B also works well for monosaccharides and maltoside.

Given the problems with purification, the use of azidoethanol as a glycosyl acceptor was also investigated. This reaction (Table 1) was much more successful and produced mainly the beta anomer 17 .

Maltoside 18 was generated by the same microwave-mediated glycosylation as developed for lactoside 16 (Method B) and in reasonable yield.

$N$-Acetyl neuraminic acid (sialic acid) is an important component of cell surfaces and chemical glycosylation procedures involving sialic acid are generally challenging. In our hands activation as the chloride (prepared from Neu5Ac in 3 steps) using silver carbonate (Method F) gave reasonable yields of 19.

\section{Deprotection reactions}

The general deprotection for compounds 10-18 is shown in Scheme 2. Acetates were cleaved using $\mathrm{NaOMe}$ followed by hydrogenation to generate $\mathbf{1}-\mathbf{8}$ in good yields.

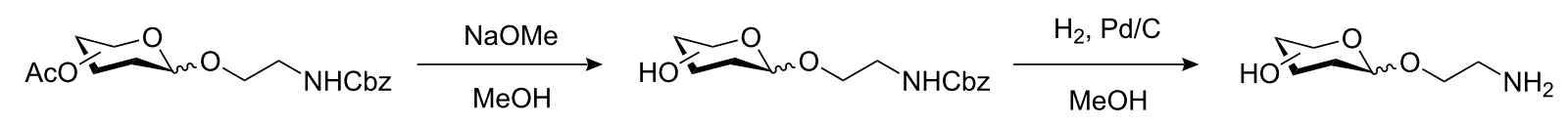


Deprotection was also successful when the hydrogenation was performed first, but in some cases migration of acetate to the aminoethyl linker was observed. However, this can be avoided by using palladium hydroxide on charcoal as the hydrogenation catalyst, with short reaction times, followed by the immediate use of the resulting amine in further coupling [18].

Sialoside 19 was deprotected by treatment with $\mathrm{NaOMe}$, followed by $\mathrm{LiOH}$ and subsequent hydrogenation to give 9 .

\section{Conclusion}

We have described rapid and convenient methods for the synthesis of a range of aminoethyl glycosides (1-9) of common mono- and disaccharides. Although some of the glycosylation reactions could be improved by using alternative glycosylation methods (such as trichloroacetimidates, thiols), these would require more steps with chromatographic purifications and less overall yields. These aminoethyl glycosides are now readily accessible for incorporation into glycan arrays.

\section{Supporting Information}

A Supporting Information containing all experimental details and analytical data of all compounds described in the article as well as their precursors is available.

\section{Supporting Information File 1}

Experimental procedures and analytical data [http://www.beilstein-journals.org/bjoc/content/ supplementary/1860-5397-6-81-S1.pdf]

\section{Acknowledgements}

We are grateful to the EPSRC, BBSRC, EC (Marie Curie ITN) and Royal Society (Wolfson Merit Award to SLF) for funding.

\section{References}

1. Lepenies, B.; Seeberger, P. H. Immunopharmacol. Immunotoxicol. 2010, 32, 196-207. doi:10.3109/08923970903292663

2. Blixt, O.; Han, S.; Liao, L.; Zeng, Y.; Hoffmann, J.; Futakawa, S.; Paulson, J. C. J. Am. Chem. Soc. 2008, 130, 6680-6681. doi:10.1021/ja801052g

3. Huflejt, M. E.; Vuskovic, M.; Vasiliu, D.; Xu, H.; Obukhova, P.; Shilova, N.; Tuzikov, A.; Galanina, O.; Arun, B.; Lu, K.; Bovin, N. Mol. Immunol. 2009, 46, 3037-3049. doi:10.1016/j.molimm.2009.06.010

4. Bejugam, M.; Flitsch, S. L. Org. Lett. 2004, 6, 4001-4004. doi:10.1021/ol048342n

5. Macmillan, D.; Daines, A. M.; Bayrhuber, M.; Flitsch, S. L. Org. Lett. 2002, 4, 1467-1470. doi:10.1021/ol025627w

6. Hartmann, M.; Horst, A. K.; Klemm, P.; Lindhorst, T. K. Chem. Commun. 2010, 46, 330-332. doi:10.1039/b922525k
7. Zhi, Z.; Laurent, N.; Powell, A. K.; Karamanska, R.; Fais, M.; Voglmeir, J.; Wright, A.; Blackburn, J. M.; Crocker, P. R.; Russell, D. A.; Flitsch, S. L.; Field, R. A.; Turnbull, J. E. ChemBioChem 2008, 9, 1568-1575. doi:10.1002/cbic.200700788

8. Karamanska, R.; Clarke, J.; Blixt, O.; MacRae, J. I.; Zhang, J. Q.; Crocker, P. R.; Laurent, N.; Wright, A.; Flitsch, S. L.; Russell, D. A.; Field, R. A. Glycoconjugate J. 2008, 25, 69-74. doi:10.1007/s10719-007-9047-y

9. Laurent, N.; Voglmeir, J.; Wright, A.; Blackburn, J.; Pham, N. T.; Wong, S. C. C.; Gaskell, S. J.; Flitsch, S. L. ChemBioChem 2008, 9, 883-887. doi:10.1002/cbic.200700692

10. Laurent, N.; Haddoub, R.; Flitsch, S. L. Trends Biotechnol. 2008, 26 , 328-337. doi:10.1016/j.tibtech.2008.03.003

11. Laurent, N.; Voglmeir, J.; Flitsch, S. L. Chem. Commun. 2008, 4400-4412. doi:10.1039/b806983m

12. Laurent, N.; Haddoub, R.; Voglmeir, J.; Wong, S. C. C.; Gaskell, S. J.; Flitsch, S. L. ChemBioChem 2008, 9, 2592-2596. doi:10.1002/cbic.200800481

13. Ni, J.; Singh, S.; Wang, L.-X. Bioconjugate Chem. 2003, 14, 232-238. doi:10.1021/bc025617f

14. Sanki, A. K.; Mahal, L. K. Synlett 2006, 455-459. doi:10.1055/s-2006-926264

15. Orlandi, S.; Annuziata, R.; Benaglia, M.; Cozzi, F.; Manzoni, L. Tetrahedron 2005, 61, 10048-10060. doi:10.1016/j.tet.2005.08.018

16. Park, S.; Shin, I. Org. Lett. 2007, 9, 1675-1678. doi:10.1021/ol070250।

17. Chernyak, A. Y.; Sharma, G. V. M.; Kononov, L. O.; Krishna, P. R.; Levinsky, A. B.; Kochetkov, N. K.; Rama Rao, A. V. Carbohydr. Res. 1992, 223, 303-309. doi:10.1016/0008-6215(92)80029-Z

18. Noble, G. T.; Flitsch, S. L.; Liem, K. P.; Webb, S. J. Org. Biomol. Chem. 2009, 7, 5245-5254. doi:10.1039/b910976e

\section{License and Terms}

This is an Open Access article under the terms of the Creative Commons Attribution License (http://creativecommons.org/licenses/by/2.0), which permits unrestricted use, distribution, and reproduction in any medium, provided the original work is properly cited.

The license is subject to the Beilstein Journal of Organic Chemistry terms and conditions:

(http://www.beilstein-journals.org/bjoc)

The definitive version of this article is the electronic one which can be found at: doi:10.3762/bjoc. 6.81 